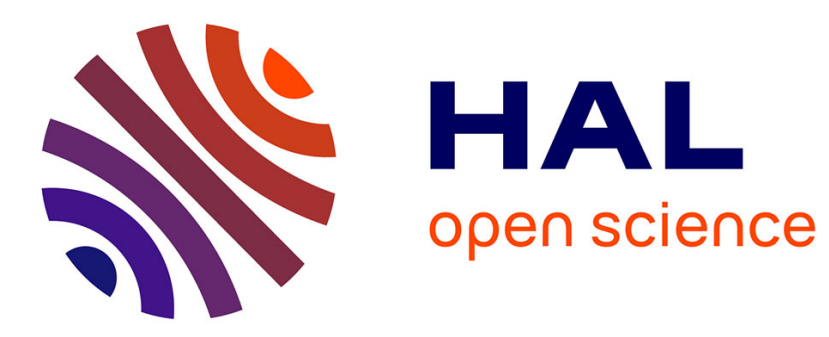

\title{
Hybrid Polymeric Nanostructures Stabilized by Zirconium and Gadolinium Ions for Use as Magnetic Resonance Imaging Contrast Agents
}

Marjorie Yon, Stéphane Gineste, Giacomo Parigi, Barbara Lonetti, Laure Gibot, Daniel Talham, Jean-Daniel Marty, Christophe Mingotaud

\section{To cite this version:}

Marjorie Yon, Stéphane Gineste, Giacomo Parigi, Barbara Lonetti, Laure Gibot, et al.. Hybrid Polymeric Nanostructures Stabilized by Zirconium and Gadolinium Ions for Use as Magnetic Resonance Imaging Contrast Agents. ACS Applied Nano Materials, 2021, 4 (5), pp.4974-4982. 10.1021/acsanm.1c00495 . hal-03265559

\section{HAL Id: hal-03265559 \\ https://hal.science/hal-03265559}

Submitted on 16 Nov 2021

HAL is a multi-disciplinary open access archive for the deposit and dissemination of scientific research documents, whether they are published or not. The documents may come from teaching and research institutions in France or abroad, or from public or private research centers.
L'archive ouverte pluridisciplinaire HAL, est destinée au dépôt et à la diffusion de documents scientifiques de niveau recherche, publiés ou non, émanant des établissements d'enseignement et de recherche français ou étrangers, des laboratoires publics ou privés. 


\title{
Hybrid Polymeric Nanostructures Stabilized by Zirconium and Gadolinium ions for Use as Magnetic Resonance Imaging Contrast Agents
}

\author{
Marjorie Yon ${ }^{\&}$, Stéphane Gineste ${ }^{\&}$, Giacomo Parigi ${ }^{\#}$, B. Lonetti ${ }^{\&}$, Laure Gibot ${ }^{\&}$, Daniel R. Talham ${ }^{\S}$, \\ Jean-Daniel Marty*\&, Christophe Mingotaud*\& \\ ${ }^{\&}$ Laboratoire des IMRCP \\ CNRS UMR 5623, University of Toulouse, Université Toulouse III - Paul Sabatier \\ 118, route de Narbonne 31062 Toulouse Cedex 9, France \\ \# Magnetic Resonance Center (CERM) and Interuniversity Consortium for Magnetic Resonance of Metallo Proteins \\ (CIRMMP), Via L. Sacconi 6, 50019 Sesto Fiorentino, Italy \\ Department of Chemistry “'Ugo Schiff”, University of Florence, Via della Lastruccia 3, 50019 Sesto Fiorentino, Italy \\ $\S$ Department of Chemistry \\ University of Florida, Gainesville, FL 32611-7200, USA
}

KEYWORDS polymer, micelle, nanoparticle, MRI, contrast agent, zirconium, gadolinium

\begin{abstract}
Nanostructures called hybrid polyion complexes (HPICs) are formed by adding metal ions to a solution of a double-hydrophilic block copolymer leading to the spontaneous formation of highly monodisperse nano-objects. In this paper, we propose a simple strategy based on a mixture of metal ions: one chosen to achieve high chemical stability of the nanoobjects and the second included to provide a desired property to the nanostructure. Using poly(ethylene oxide)-b-poly(acrylic acid) as the copolymer, zirconium ion added as $\mathrm{ZrO}^{2+}$, was selected to insure strong interactions with the polymers to reinforce the stability of the HPIC architecture. The zirconyl ions were combined with lanthanide ions, which are often used in contrast agents for proton-magnetic resonance imaging. Mixing the two metal ions with the copolymer led to nano-objects with an average radius of ca 11-16 $\mathrm{nm}$. Increasing the zirconyl mole fraction inside the HPICs leads to excellent chemical stability of the nano-objects. Unexpectedly, when paired with $\mathrm{Gd}^{3+}$, the mixed metal HPIC exhibits greatly enhanced magnetic relaxivity relatively to the single ion $\mathrm{Gd}^{3+} \mathrm{HPIC}$, when the zirconyl mole fraction increases. This behavior was further studied by nuclear magnetic relaxation dispersion. The resulting nano-objects are excellent contrast agent with a good biocompatibility. In addition, there is significant potential for extending the mixed metal HPIC platform to other areas of study.
\end{abstract}

\section{INTRODUCTION}

Surfactants or polymers self-assemble in water leading to a variety of architectures with characteristic length scales from nanometers to micrometers. ${ }^{1}$ When the polymers are ionic or double hydrophilic block copolymers with an ionic block, they can co-assemble with compounds bearing the opposite charges producing nano-colloids named coacervates or polyion complexes. $^{2}$ The nature of the oppositely charged component ranges widely, with examples including polymers and dendrimers, biopolymers including DNA and proteins, surfactants, nanoparticles, molecular complexes and polyvalent metal ions. The choice of block copolymer and counter ion partner allows dramatic modulation of structure and function, although to date, most achievements take advantage of components with biological compatibility and biodegradability for biotechnology applications, often involving payload delivery.

When the counter ions are simple polyvalent metal ions, block copolymers bearing negative charges can form micelle like nanostructures called hybrid polyion complexes (HPICs). Examples with $\mathrm{Mn}^{2+} ; \mathrm{Cu}^{2+}, \mathrm{Zn}^{2+}, \mathrm{Pt}^{2+}, \mathrm{Ca}^{2+}, \mathrm{Al}^{3+}$ and lanthanide ions have been used to form such nanostructures. ${ }^{3-8}$ However, despite their relative simplicity, compared to other polyion complexes there has been relatively little focus on HPIC's, and even among those examples, most use the HPIC's as intermediates to subsequently form metal, semiconductor, or other mineral nanoparticles stabilized by the polymeric coating. Nevertheless, there is interest in simple HPICs wherein the complexed metal ions or metal complexes are the active elements, for example in catalysis and sensing, or in imaging as was recently demonstrated with a $\mathrm{Gd}^{3+}$ HPIC MRI contrast agent. ${ }^{2,9}$

The potential of mixed metal HPICs as a route to enhance function is largely unexplored. Formed from double hydrophilic block copolymers with a binary mixture of ions, the metal ions can be selected in order to confer a given property or a combination of properties to the final assembly. In this study, we 
demonstrate the potential of mixed metal HPIC's starting with the diblock polymer poly(ethylene oxide)-b-poly(acrylic acid) $\left(\mathrm{PEO}_{6 \mathrm{k}}-\mathrm{b}-\mathrm{PAA} \mathrm{A}_{3 \mathrm{k}}\right)$ complex with lanthanide ions and compare the nanostructure and properties of the mixed lanthanide $/ \mathrm{ZrO}^{2+}$ HPIC. This system was chosen because examples of HPICs formed from $\mathrm{Gd}^{3+}$ and PEO-b-PAA were shown to be effective $\mathrm{T}_{1}$ MRI contrast agents in vitro and in vivo. ${ }^{9}$ These HPICs have a well-defined radius of ca $11 \mathrm{~nm}$ and their external PEO shell makes them biocompatible with low toxicity. Importantly, the T1-weighted enhancement seen with the $\mathrm{Gd}^{3+}$ HPIC's is largely independent of external magnetic field. Although promising, the initial HPIC systems are far from optimized and a key concern is the stability of the hybrid micelles. Zirconyl ion was chosen to enhance the stability of the HPIC nanoarchitecture as polymers bearing carboxylic functions have strong affinity for zirconium ions, ${ }^{10-11}$ while at the same time zirconium ions have long been used in medical applications without reported adverse effects. ${ }^{12}$ As shown in the following sections, consistent with our hypothesis, this mixed metal strategy (see Figure 1) greatly enhances the stability of the HPIC nano-objects. However, an unexpected result is that the mixed metal HPICs also exhibit astonishingly improved proton relaxivity relative to the already impressive single ion $\mathrm{Gd}^{3+}$ HPICs. To better understand this behavior, nuclear magnetic relaxation dispersion profiles are used to compare the single ion and mixed metal HPICs.

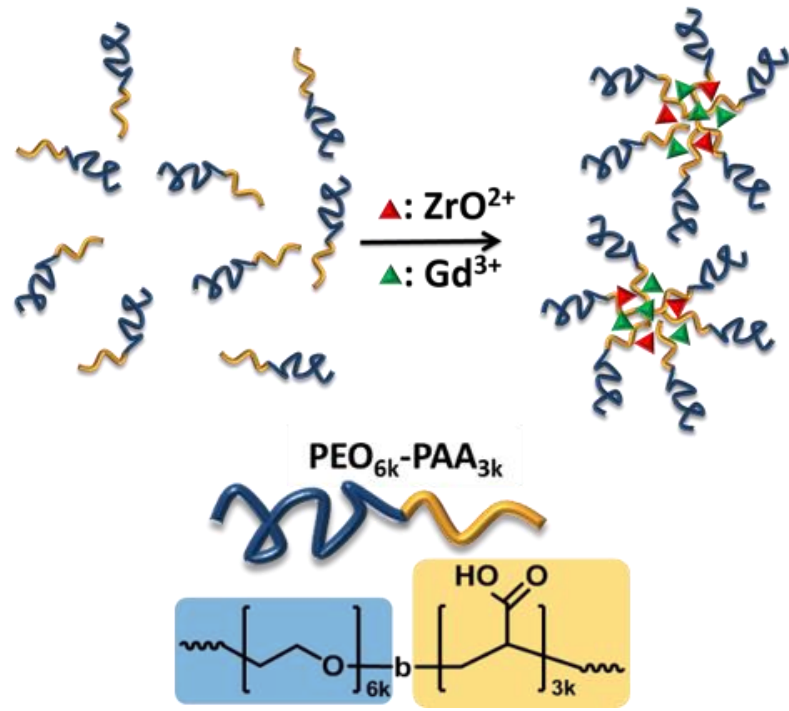

Figure 1. Strategy used to develop efficient hybrid micelles. Mixtures of gadolinium and zirconyl ions are added to a double hydrophilic block copolymer $\left(\mathrm{PEO}_{6 \mathrm{k}}-\mathrm{PAA}_{3 \mathrm{k}}\right.$ ) solution leading to spontaneous assemblies of HPICs (hybrid polyion complexes).

\section{RESULTS AND DISCUSSION}

\section{Size, structure and stability}

To form the HPIC nano-objects, a mixture of $\mathrm{Gd}^{3+}$ and $\mathrm{ZrO}^{2+}$ ions, with a mole fraction of gadolinium noted $\rho_{\mathrm{Gd}}$, is added to an aqueous solution of the diblock $\mathrm{PEO}_{6 \mathrm{k}}-\mathrm{b}-\mathrm{PAA}_{3 \mathrm{k}}$ copolymer $(0.1 \% \mathrm{wt})$. Electroneutrality is set between the positive charges due to the inorganic ions and the potentially available negative charges from the ionized or ionizable acrylic acid monomer units (AA). In other words, the ratio $\rho_{\text {charge }}$ was chosen to be close to unity:

$$
\begin{aligned}
& \rho_{\text {charge }}=\left(3\left[\mathrm{Gd}^{3+}\right]+2\left[\mathrm{ZrO}^{2+}\right]\right) /[\mathrm{AA}]=1 \\
& \rho_{\mathrm{Gd}}=\left[\mathrm{Gd}^{3+}\right] /\left(\left[\mathrm{Gd}^{3+}\right]+\left[\mathrm{ZrO}^{2+}\right]\right)
\end{aligned}
$$

For all $\rho_{\mathrm{Gd}}$ values, well-defined HPICs were formed. For pure Gd HPICs $\left(\rho_{\mathrm{Gd}}=1\right)$, a radius of ca $11 \mathrm{~nm}$ is determined from DLS experiments. When the mole fraction $\rho_{\mathrm{Gd}}$ decreases, meaning the content of zirconyl ions within the HPICs increases, the radius becomes slightly larger, up to $16 \mathrm{~nm}$ (see Figure S1 and Table 1). Such change is also demonstrated by SAXS experiments which show that HPICs are nano-objects with a compact core and a highly hydrated PEO shell (see Figure S2).

Table 1. Estimated mean radius of HPIC nano-objects containing either gadolinium or europium mixed with zirconium in various mole fractions.

\begin{tabular}{ccccc}
\hline $\begin{array}{c}\mathrm{HPIC} \\
\text { radius } \\
{[\mathrm{nm}]^{\mathrm{a})}}\end{array}$ & $\begin{array}{c}\rho_{\mathrm{M}}=100 \% \\
\text { (pure Gd or } \\
\text { Eu HPIC) }\end{array}$ & $\rho_{\mathrm{M}}=50 \%$ & $\rho_{\mathrm{M}}=10 \%$ & $\begin{array}{c}\rho_{\mathrm{M}}=0 \% \\
\text { (pure Zr } \\
\text { HPIC) }\end{array}$ \\
\hline $\mathrm{M}=\mathrm{Gd}$ & $11.5 \pm 1.2$ & $13.6 \pm 1.7$ & $15.9 \pm 1.9$ & $15.1 \pm 2.0$ \\
$\mathrm{M}=\mathrm{Eu}$ & $13.7 \pm 1.1$ & $12.9 \pm 1.7$ & $15.7 \pm 1.7$ & $15.1 \pm 2.0$ \\
\hline
\end{tabular}

a) Radius (and standard deviation) estimated by cumulant analysis of multi-angle DLS experiments of HPIC containing either gadolinium or europium ( $\mathrm{M}=\mathrm{Gd}$ or Eu) and zirconium ( $\mathrm{Zr}$ ). The molar fraction of Gd or Eu is noted $\rho_{\mathbf{M}}$. NNLS analysis of DLS data lead to slightly larger radii, up to $20 \mathrm{~nm}$ for the pure $\mathrm{Zr}$ HPIC system.

The explanation of the size difference is complicated by uncertainty surrounding the precise form of zirconium ions, $\mathrm{ZrO}^{2+}$ or $\mathrm{Zr}^{4+}$, in acetate complexes. ${ }^{10,13-17}$ Even if the exact state of the zirconium ions within the HPICs is unknown, the presence of such ions has a paramount effect on the chemical stability of these nano-objects. As shown in Figure 2, decreasing the $\mathrm{pH}$ below 4 of a pure Gd HPIC solution induces a large increase in Z-average size measured by DLS. This behavior is explained by the chemical neutralization of the carboxylate functions leading to the destabilization and destruction of the HPIC nanoobjects. The release of free copolymers induces the formation of very large undefined aggregates of polymers, which explains the strong increase in the $\mathrm{Z}$ average values. The $\mathrm{pK}_{\mathrm{a}}{ }^{0}$ of PAA is expected to be around 4.3-4.5. ${ }^{18-19}$ In HPICs, the neutralization of the carboxylate described by the following equation:

$$
\mathrm{H}^{+}+\mathrm{Gd}^{-\mathrm{RCOO}^{-}}=\mathrm{Gd}_{\text {free }}+\mathrm{RCOOH}
$$

is associated with an apparent $\mathrm{pK}_{\mathrm{a}}^{\mathrm{app}}$ of the carboxylic functions. From Figure 2, we can assume that $\mathrm{pK}_{\mathrm{a}}$ app is lower than 4. The difference $\mathrm{pK}_{\mathrm{a}}{ }^{0}-\mathrm{pK}_{\mathrm{a}}^{\mathrm{app}}$ is linked to the strength of the metal ion/carboxylate interactions. When zirconyl is added, the neutralization of the PAA polymers becomes more difficult and is even not observed for $75 \% \mathrm{Zr}-25 \%$ Gd HPICs, which are perfectly stable at $\mathrm{pH}$ as low as 1.5 . Therefore, the difference $\mathrm{pK}_{\mathrm{a}}{ }^{0}-\mathrm{pK}_{\mathrm{a}}^{\mathrm{app}}$ is much larger with $\mathrm{ZrO}^{2+} / \mathrm{Zr}^{4+}$ than for $\mathrm{Gd}^{3+}$, demonstrating stronger interactions between the zirconyl ions and the carboxylate functions. In brief, when the $\mathrm{Zr}$ content in the HPICs is increased, the nano-objects are increasingly stable. However, either with or without zirconyl, gadolinium appears to be released from the HPICs for $\mathrm{pH}$ less than 4 (see Figure $\mathrm{S} 3$ ): the $\mathrm{pK}_{\mathrm{a}}$ app of the carboxylic functions interacting with $\mathrm{Gd}^{3+}$ is not modified by the HPIC structure induced by the zirconyl ions.

Due to the similar chemical behavior of europium and gadolinium ions, ${ }^{20} \mathrm{Eu}$ HPICs should provide a good structural model for Gd HPICs, enabling europium fluorescence as a tool for elucidating details of the metal ion coordination. 


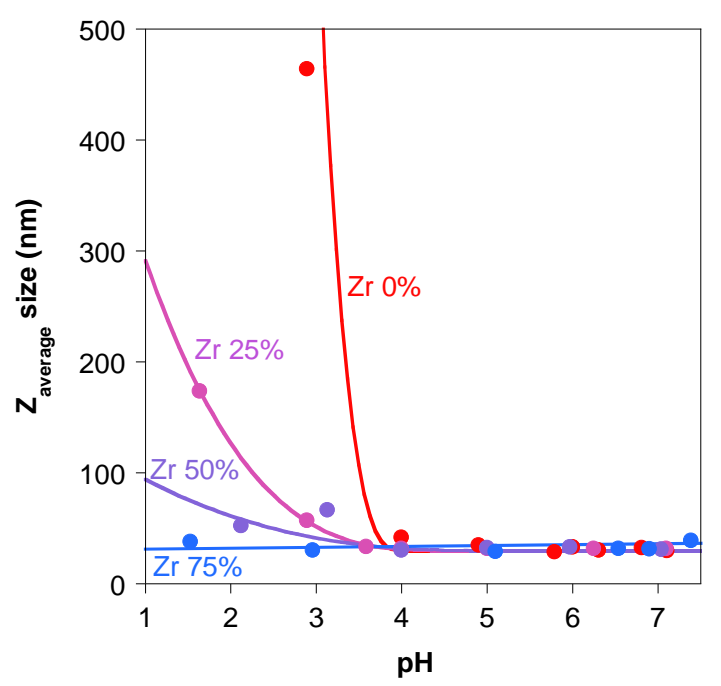

Figure 2. Effect of $\mathrm{pH}$ on the average size of the nano-objects contained in solutions of HPICs with gadolinium and zirconyl ions in various molar proportions (full circle: $100 \% \mathrm{Gd}-0 \% \mathrm{Zr}$; open circle: $75 \%-25 \% \mathrm{Zr}$; full square: $50 \% \mathrm{Gd}-50 \% \mathrm{Zr}$; open square: $25 \% \mathrm{Gd}-75 \% \mathrm{Zr}$ ). The average size is the $\mathrm{Z}$ average diameter measured by a single-angle DLS apparatus. Lines are just guides for the eye.

As shown in Table 1, both assemblies indeed have similar size. Europium luminescence experiments on Eu HPIC solutions were performed in water and heavy water in order to estimate the number of water molecules bound to lanthanide ions. ${ }^{21}$ Since radiationless de-excitation due to $\mathrm{OH}$ groups in the inner sphere of the lanthanide is more effective than OD, the difference between lifetimes in $\mathrm{H}_{2} \mathrm{O}$ or in $\mathrm{D}_{2} \mathrm{O}$ is related to the number of water linked to the lanthanide. ${ }^{22}$ For Eu-Zr mixed HPICs, the lifetime $\tau_{\mathrm{H}_{2} \mathrm{O}}$ was found close to $0.22 \pm 0.02 \mathrm{~ms}$ whereas $\tau_{\mathrm{D}_{2} \mathrm{O}}$ is $1.95 \pm 0.38 \mathrm{~ms}$.

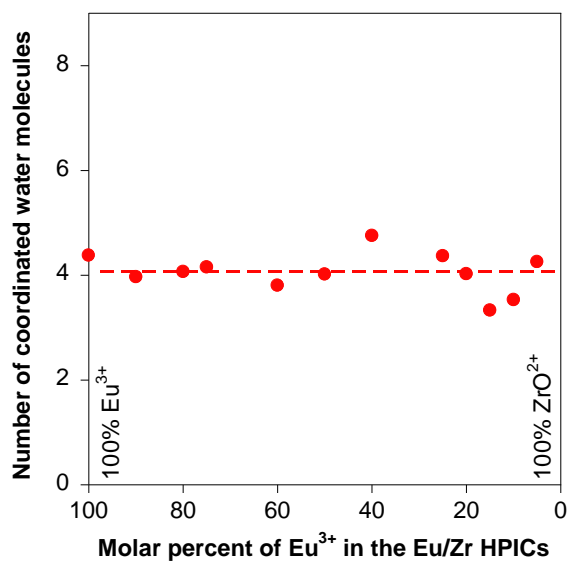

Figure 3. Determination of the number of coordinated water molecules on the europium ions inside mixed $\mathrm{Zr}$ - Eu HPICs. The mean value of this number (corresponding to the dashed line) is $4.1 \pm$ 0.4 .
Using the equation proposed by R.M. Supkowski et al., ${ }^{23}$ the number (n) of water molecules coordinated to the europium ions within the HPICs was estimated by:

$$
\mathrm{n}=1.11 *\left[1 / \tau_{\mathrm{H}_{2} \mathrm{O}}-1 / \tau_{\mathrm{D}_{2} \mathrm{O}}-0.31\right]
$$

This number is found equal to $4.1 \pm 0.4$ (see Figure 3 ) and remains constant for all $\rho_{\mathrm{Eu}}$. If we assume the water coordination number is also the same for gadolinium in HPICs, the first coordination sphere of gadolinium contains 4 water molecules and an average of 3 carboxylate functions, as expected from electroneutrality, in an eight or nine coordinate complex typical for lanthanides, and does not appear to change with $\rho_{\mathrm{Gd}}$.

\section{Magnetic Relaxivity}

Contrast agents help enhance the accuracy of the MRI diagnoses, thanks to their capability to locally decrease the proton relaxation times in normal or pathological tissues. ${ }^{24}$ Positive contrasts $^{25}$ (i.e. induced by the changes in longitudinal magnetic relaxation, $\mathrm{T}_{1}$, of the contrast agent) are often preferred as they are easier to detect than changes in transverse magnetic relaxation, $\mathrm{T}_{2} .{ }^{26-27}$ The efficiency of a contrast agent is determined by the longitudinal and transverse relaxivities, $r_{1}$ and $r_{2}$, respectively, defined as the paramagnetic relaxation enhancements in the longitudinal and transverse relaxation rates of water protons at one millimolar concentration of the agent. ${ }^{28}$ As discussed further below, nanoparticles based on $\mathrm{Gd}^{3+}$ are often employed as $\mathrm{T}_{1}$ agents. ${ }^{29}$ However, the potential toxicity of metallic ions ${ }^{30}$ such as $\mathrm{Gd}^{3+}$ on living systems has been known since the 1960 's. ${ }^{31-33}$ Therefore, the challenge to develop new safer contrast agents with lower Gd-ion content but similar or better performance is again a high priority. This challenge should also take into account the tendency toward higher magnetic fields in modern MRI scanners. While improving image resolution, higher magnetic fields result in less efficient relaxation processes and a dramatic decrease of the longitudinal relaxivity. ${ }^{34}$

Although the zirconyl content has no effect on the first coordination sphere of gadolinium ions, it clearly affects the magnetic properties of the HPICs. The water proton relaxivity at 1.4 $\mathrm{T}$ almost doubles when adding zirconium in the HPICs (Figure 4), with a first increase as the zirconium mole fraction reaches ca $50 \%$ and then a second increase as the zirconium content tends to $100 \%$.

As shown in Figure 4, a decrease of gadolinium content by a factor 20 in the Gd - Zr HPIC system effectively doubles the relaxivity. Although it is nonmagnetic, the presence of zirconium ion appears to play an important role in this astonishing result. Indeed, when the nonmagnetic ion $\mathrm{Ga}^{3+}$ is used instead of the zirconyl, the relaxivity increases up to a maximum of $30 \%$, but is followed by a large decrease for higher fraction of gallium (see Figure 4), in contrast to the response seen for the $\mathrm{Gd}-\mathrm{Zr}$ HPICs. To better understand the magnetic properties of the $\mathrm{Gd}-\mathrm{Zr}$ systems, nuclear magnetic relaxation dispersion (NMRD) experiments were performed. 

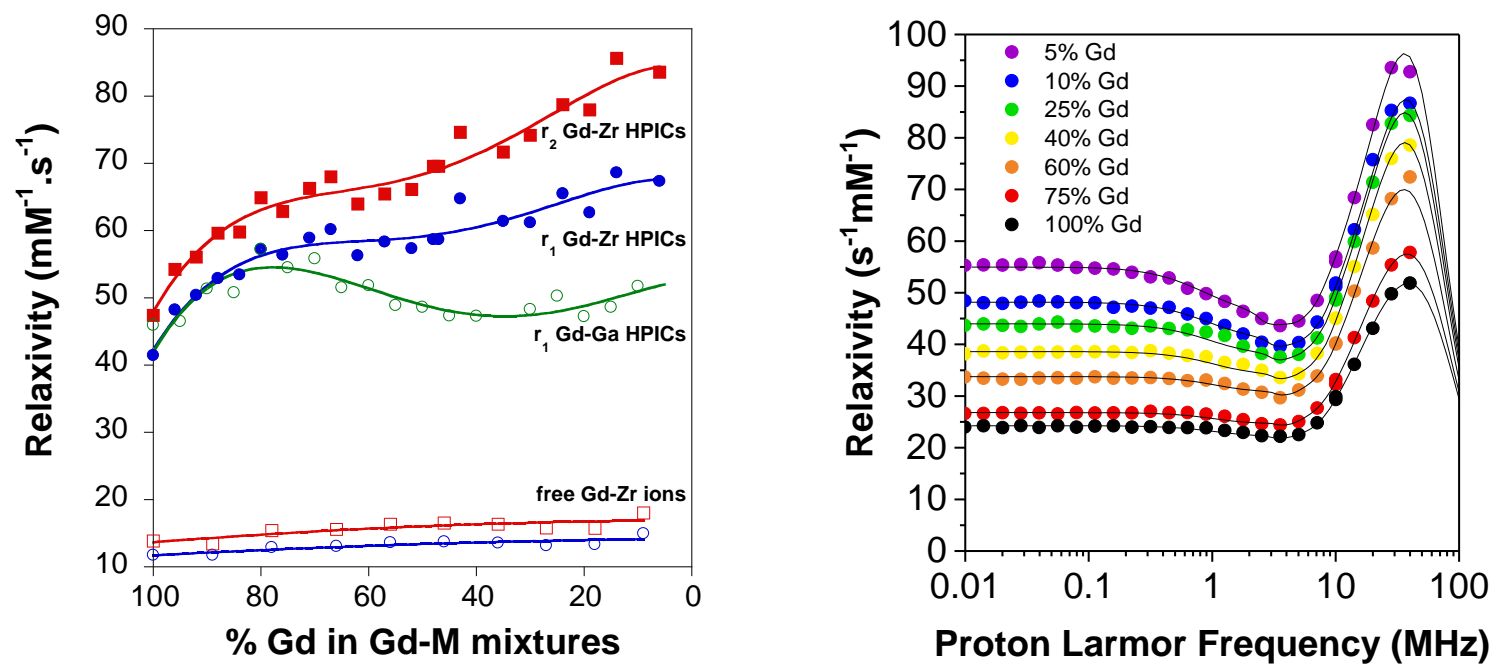

Figure 4. (Left) Longitudinal and transverse relaxivity measurements at $1.4 \mathrm{~T}$ and $25^{\circ} \mathrm{C}$ of $\mathrm{Gd}-\mathrm{Zr}$ or Gd-Ga HPICs and simple $\mathrm{Gd}-\mathrm{Zr}$ ion mixtures in water (i.e. without copolymers) for various molar fractions of gadolinium. Full red square: $r_{2}$ of Gd-Zr HPICs, full blue circles $r_{1}$ of Gd $-\mathrm{Zr}$ HPICs, open green circles $r_{1}$ of Gd - Ga HPICs, open red square: $r_{2}$ of Gd $-\mathrm{Zr}$ solutions without polymer, open blue circles $\mathrm{r}_{1}$ of $\mathrm{Gd}-\mathrm{Zr}$ solutions without polymer. The relaxivity is expressed per mol of $\mathrm{Gd}^{3+}$ ion. Lines are just guides for the eye. (Right) NMRD profiles of Gd $-\mathrm{Zr} \mathrm{HPICs}$ solution at $25^{\circ} \mathrm{C}$ for various mole fractions of gadolinium. The lines are the results of the fitting by the NMRD model (see experimental section).

Table 2. Relaxation parameters deduced from NMRD profiles obtained on Gd-Zr HPIC solutions. ${ }^{\text {a) }}$

\begin{tabular}{llllllll}
\hline$\rho_{\mathrm{Gd}}$ & $5 \%$ & $10 \%$ & $25 \%$ & $40 \%$ & $60 \%$ & $75 \%$ & $100 \%$ \\
\hline$\Delta_{\mathrm{t}}\left(\mathrm{cm}^{-1}\right)$ & 0.022 & 0.023 & 0.024 & 0.026 & 0.029 & 0.032 & 0.036 \\
$\tau_{v}(\mathrm{ps})$ & 10 & 11 & 13 & 16 & 23 & 23 & 26 \\
$\tau_{R}(\mathrm{~ns})$ & & & & & & & \\
\hline$\tau_{M}(\mu \mathrm{s})$ & 0.47 & 0.54 & 0.57 & 0.64 & 0.76 & 0.96 & 1.1 \\
\hline $\mathrm{ZFS}\left(\mathrm{cm}^{-1}\right)$ & 0.047 & 0.055 & 0.057 & 0.060 & 0.064 & 0.065 & 0.067 \\
$\theta\left(^{\circ}\right)$ & 61 & 64 & 63 & 61 & 58 & 62 & 60
\end{tabular}

a) $\Delta_{t}$ mean squared fluctuation of the transient ZFS; $\tau_{V}$ correlation time of the instantaneous distortion of the gadolinium coordination polyhedron; $\tau_{R}$ rotational correlation time; $\tau$ M proton exchange lifetime ZFS static zero-field splitting parameter; $\theta$ polar angle describing the orientation of the principal static ZFS axis with respect to the principal dipole-dipole axis of the proton and electron spin; fixed parameters: $3.05 \AA$ for the distance between the gadolinium atom and the protons in fast exchange, 4 water molecules coordinated to the gadolinium atom.

As shown in Figure 4, the NMRD profiles have the typical high field peak which is present when the field dependent electron relaxation time of gadolinium is shorter than the reorientation time of the nanoparticles. In this case, the electron relaxation time dictates the correlation time for the dipole-dipole interaction between the electron magnetic moment and the nuclear magnetic moment. In general, an increase of the reorientation time, $\tau_{R}$, yields a larger $\mathrm{r}_{1}$ at low fields, provided the lifetime is shorter than the $\mathrm{T}_{1}$ of the dipole-dipole interacting protons, although it can result in a smaller $r_{1}$ at high fields. ${ }^{35-37}$ Strategies to graft the Gd complexes to large or rigid molecules or macromolecules, ${ }^{38-43}$ or to confine the complexes, ${ }^{44-45}$ have been shown to increase the value of $\tau_{R}$ and thus enhance the efficiency contrast agents up to fields of about $1 \mathrm{~T}$. The tunability of co-polymers or of multi-block copolymers has therefore logically led to efforts to form polymers with a high loading of gadolinium complexes, ${ }^{46-48}$ similar to our original motivation for exploring Gd-HPICs. The rotational correlation time of the HPICs, expected of several ns, is considerably larger than for DOTAREM $(0.2 \mathrm{~ns})$ or Magnevist $(0.05 \mathrm{~ns}) .{ }^{35}$ The globular structure as well as the localization of the gadolinium at the barycenter of the HPICs are in favor of a much larger $\tau_{\mathrm{R}}$ as well as an increase of the relaxivity. ${ }^{49}$ The NMRD profiles were fitted according to the modified Florence NMRD model, which takes into account the effect of static zero field splitting, with four water molecules regularly coordinated to the $\mathrm{Gd}^{3+}$ ion. The obtained best fit values are reported in Table 2. As expected, the profiles are reproduced with a rotational correlation time of several ns. Notably, it was impossible to fit all profiles with the same electron relaxation parameters $\left(\Delta_{\mathrm{t}}\right.$ and $\left.\tau_{\mathrm{v}}\right)$. The estimated values of $\Delta_{\mathrm{t}}$ and $\tau_{\mathrm{v}}$ in pure Gd HPICs are close to those of commercially available Gd-contrast agents ${ }^{50}$ and drop by ca $30 \%$ when $95 \%$ of the gadolinium is replaced by zirconyl. The smaller electron relaxation times, determined from the values of $\Delta_{\mathrm{t}}$ and $\tau_{\mathrm{v}}$, with increasing the gadolinium content suggests that magnetic coupling occurs in pure Gd HPICs and that the coupling decreases with increasing zirconyl concentration. The result is lower efficiency of each paramagnetic site when the $\mathrm{Gd}^{3+}$ ions are close to one another at the core of the nano-object than when the sites are well separated. In other words, the addition of $\mathrm{ZrO}^{2+}$ separates the $\mathrm{Gd}^{3+}$ ions thereby enhancing the efficiency of each individual ion. This effect is also partially observed with gallium ions (Figure 4). 
The fit also shows a decrease in the lifetime of the coordinated protons $\left(\tau_{\mathrm{M}}\right)$, and thus an increase in the water proton exchange rate, on passing from $100 \%$ to $5 \%$ gadolinium. This increase may partially compensate for the neglected and unknown coefficient in the expression for the electron-nucleus dipole-dipole relaxation, resulting from the magnetic coupling between electron spins and depending on the populations of the electron spin levels of the magnetically coupled system.. ${ }^{51-52}$ On the other hand, such a change in the $\tau_{\mathrm{M}}$ may be due to the large change in the gadolinium environment when zirconyl are present. Indeed, water diffusion within the polymeric PEOPAA assemblies should be slower compared to bulk water diffusion. The polymer chains impose physical barriers as well as provide hydrogen binding sites that slow water diffusion in and out of the nano-objects. Furthermore, a high density of metal ions can cause water molecules to coordinate the metals multiple times while within the nano-object, further slowing the effective water exchange with the bulk. Whereas the $\mathrm{Gd}^{3+}$ ions coordinate four water molecules, the zirconium ions are expected to bind fewer, one or two at most. This would favor a faster water exchange between the bulk and the nano-objects as the zirconyl content increases. Whatever the exact origin of this change in $\tau_{\mathrm{M}}$, the values estimated for the HPICs with just a few percent of gadolinium ions are close to those of many $\mathrm{Gd}$ complexes used as MRI contrast agents. ${ }^{50}$

The $5 \% \mathrm{Gd}-95 \% \mathrm{Zr}$ HPICs have a magnetic relaxivity much higher than that of DOTAREM (ca $\left.4 \mathrm{mM}^{-1} \cdot \mathrm{s}^{-1}\right)$ and close to that of the most efficient agents proposed in the literature ${ }^{53}$ but with a much lower Gd loading. For this mole fraction, the average polymer chain contains one gadolinium ion and 19 zirconyl ions. Therefore, this system has a gadolinium load of $1.4 \%$ in weight, much lower than the ca $28 \%$ for DOTAREM, $20 \%$ for the pure Gd HPICs, or 7-8 \% for star polymers or dendrimers loaded in gadolinium ${ }^{40,54}$.

Besides these excellent relaxivity properties, these HPICs are also biocompatible. As shown in Figure 5, the mixtures of gadolinium and zirconyl ions present statistically significant toxicity on the human HCT-116 colorectal cancer cells at high concentrations. This is expected from the slight toxicity of zirconyl chloride $^{55}$ added to the one of gadolinium. Similar results are found for the PEO-PAA copolymer alone. However, the HPICs made by mixing ions and copolymers have no statistically relevant toxicity outside of a slight decrease in the cell viability is observed for the highest concentrations. The PEO shell of the HPICs is thus responsible for such decrease in the toxicity. High relaxivity and low toxicity make these HPICs highly promising for MRI and in vivo experiments on animals are planned.

\section{CONCLUSIONS}

We demonstrate that nano-objects made of double hydrophilic block copolymers organized by zirconyl ions and containing a low mass ratio of gadolinium ions are highly stable in vitro with a well-defined radius between 11 and $16 \mathrm{~nm}$. Their astonishing efficiency of the nano-objects as potential MRI contrast agents was demonstrated in solution where the low gadolinium content clearly improved their magnetic properties as well as stability. This efficiency may be due to a larger average distance between gadolinium ions, increasing the effectiveness of each gadolinium site, combined with more efficient water diffusion within the polymer matrix due to a lower number of water complexation sites in the polymer assemblies when zirconyl is mixed with gadolinium. Such results demonstrate the efficiency of the proposed strategy: combining ions having different roles within the HPICs. They show the potentiality of the HPIC platform which can lead to nano-objects designed for many type of applications and functionality.
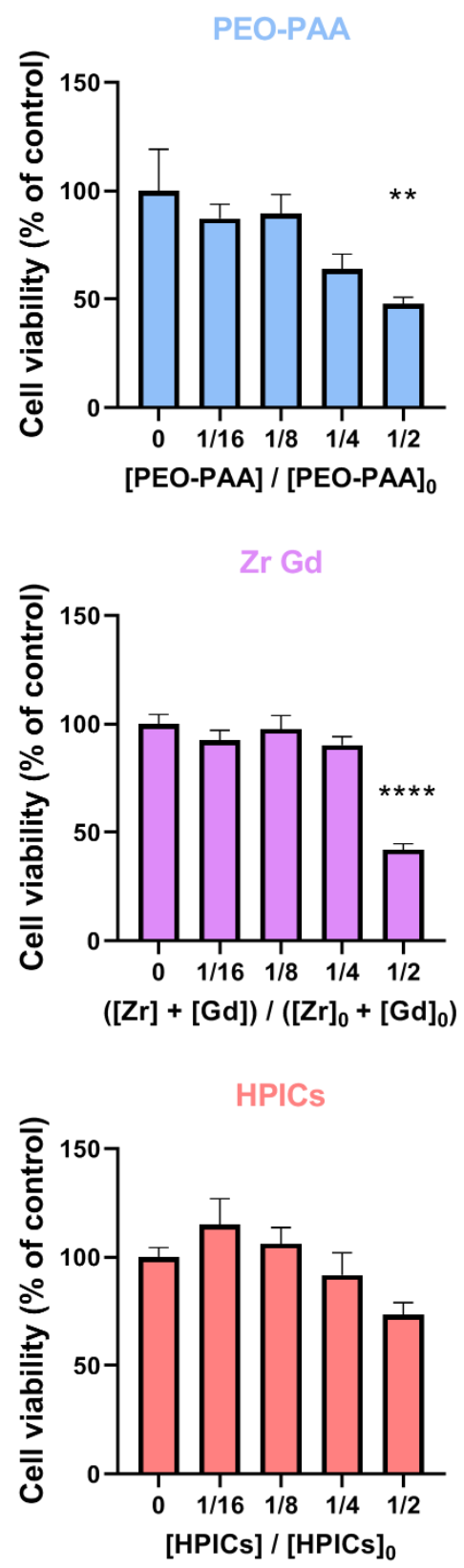

Figure 5. Cytotoxicity of the $\mathrm{Zr}-\mathrm{Gd}$ HPICs with molar ratio $2 / 3 \mathrm{Zr}$ and $1 / 3 \mathrm{Gd}$ and of its individual components assessed in vitro on human HCT-116 colorectal cancer cells after $24 \mathrm{~h}$ of incubation. Top: Polymer alone with $[\mathrm{PEO}-\mathrm{PAA}]_{0}=0.18 \%$ wt. Middle: a mixture of zirconyl and gadolinium ions with $[\mathrm{Zr}]_{0}=3.35 \mathrm{mM}$ and $[\mathrm{Gd}]_{0}=1.16 \mathrm{mM}$. Bottom: HPIC solution with $[\mathrm{PEO}-\mathrm{PAA}]=0.19 \%$ wt, $[\mathrm{Zr}]=3.34 \mathrm{mM}$ and $[\mathrm{Gd}]=1.11 \mathrm{mM}$ corresponding to a concentration of HPICs noted [HPICs]0. 


\section{EXPERIMENTAL SECTION}

\section{Materials}

$\mathrm{Gd}\left(\mathrm{NO}_{3}\right)_{3} \cdot 6 \mathrm{H}_{2} \mathrm{O}, \quad \mathrm{ZrOCl}_{2} \cdot 8 \mathrm{H}_{2} \mathrm{O}, \quad \mathrm{Eu}\left(\mathrm{NO}_{3}\right)_{3} \cdot 5 \mathrm{H}_{2} \mathrm{O} \quad$ and $\mathrm{Ga}\left(\mathrm{NO}_{3}\right)_{2} \cdot 6 \mathrm{H}_{2} \mathrm{O}$ were purchased from Sigma Aldrich Co., Ltd. at highest purity available and used as received. $\mathrm{PEO}_{6 \mathrm{k}}-\mathrm{b}-$ PAA $_{3 \mathrm{k}}$ was purchased from Polymer Source ${ }^{\mathrm{TM}}$ and used as received. Water was purified through a filter and ion exchange resin using a Purite device (resistivity $18.2 \mathrm{M} \Omega \cdot \mathrm{cm}$ ). $\mathrm{D}_{2} \mathrm{O}$ was obtained from Eurisotop.

\section{Characterization}

\section{Luminescence}

Luminescence lifetime measurements were performed on a LS-50B Perkin-Elmer spectrofluorimeter equipped with a xenon flash lamp source. The luminescence decays were analyzed with a single exponential function.

\section{Dynamic light scattering}

Multi-angle dynamic light scattering experiments were performed on a 3D LS spectrometer from LS instruments (Switzerland) at $20^{\circ} \mathrm{C}$. Working with a laser at $660 \mathrm{~nm}$, this instrument recorded light scattering for scattering angles between 15 and $150^{\circ}$. Typical acquisition time for each angle was set to $30 \mathrm{~s}$. All DLS data were then analyzed using a laboratory made software program (named M-STORMS) ${ }^{56}$ Cumulant or NNLS method led to an estimation of the decay rate $\Gamma$ for each angle. The linear dependency of $\Gamma$ versus the square of the scattering vector q gives the diffusion coefficient of the nano-objects and therefore their radius through the Stokes-Einstein equation. Generally, the correlograms correspond to a simple narrow distribution in size (around 10-20 nm). Rarely, for low angles, a second peak (around 100-150 nm) was detected which can often disappear by a simple filtration of the samples. When present, the concentration of such larger objects was near or less than $10^{-4} \%$ of the concentration of the HPICs.

\section{Small Angle X-ray Scattering}

SAXS was performed at European Synchrotron Radiation Facility (ESRF) in Grenoble (beamline ID02 equipped with a Rayonix MX-170HS ccd detector to collect the 2D SAXS pattern). ${ }^{57}$ In order to guarantee an accurate background subtraction and minimize damage of the samples because of beam exposure, the solutions were loaded in a flow through capillary of $1.6 \mathrm{~mm}$ diameter. The measured SAXS profiles were normalized to an absolute scale using the standard procedure reported elsewhere. ${ }^{58}$ The SAXS utilities analysis package ${ }^{59}$ was used for averaging the intensity profiles for each sample and background scattering subtraction. A sample to detector distance of $1.5 \mathrm{~m}$ was employed in order to cover a $q$-range, $5.6 \times 10^{-2}<q$ $<5 \mathrm{~nm}^{-1}$. The scattering wave vector $q$ is defined as $q=(4 \pi / \lambda)$ $\sin \vartheta / 2,(\lambda \sim 1 \AA)$ and $\vartheta$ the scattering angle.

Inductively Coupled Plasma analysis

Inductively coupled plasma - atomic emission spectroscopy (ICP-AES) analysis were performed by Antellis company (http://www.antellis.com).

\section{Magnetic Relaxation}

Magnetic relaxation time measurements in solution were carried out at $1.4 \mathrm{~T}$ on a Minispec mq60 TD-NMR contrast agent analyzer (Bruker Optics, Billerica, MA, USA) at a constant temperature of $25^{\circ} \mathrm{C}$. $\mathrm{T}_{1}$ relaxation times were measured using an inversion recovery pulse sequence; $\mathrm{T}_{2}$ relaxation times were measured using a Carr-Purcell-Meiboom-Gill pulse sequence. The delay between the first and final pulses was set to $6500 \mathrm{~ms}$. Experiments were performed on solutions with $0.1 \%$ wt of polymers (see below).

Water ${ }^{1} \mathrm{H}$ nuclear magnetic relaxation dispersion (NMRD) profiles were acquired using a high sensitivity fast field cycling relaxometer (Stelar, Mede, Italy). The longitudinal relaxation rates were extracted by single exponential fitting of magnetization decay or magnetization build-up curves at ${ }^{1} \mathrm{H}$ Larmor frequencies ranging from 0.01 to $40 \mathrm{MHz}$. The errors of the collected relaxation rates were below $1 \%$.

Paramagnetic relaxivity profiles were calculated from the difference between the relaxation rates measured for the paramagnetic samples and those of the analog diamagnetic samples, normalized to $1 \mathrm{mM}$ gadolinium( $3+$ ) concentration.

The modified Florence NMRD model ${ }^{50,60-62}$, developed to analyze the paramagnetic relaxometry profiles when deviations from the Solomon-Bloembergen-Morgan (SBM) theory are expected due to the presence of static zero-field splitting (ZFS), has been used. From this analysis, the values of the reorientation time $\left(\tau_{R}\right)$, of the water proton lifetime $\left(\tau_{M}\right)$, and of the parameters describing electron relaxation $\left(\Delta_{\mathrm{t}}\right.$ and $\left.\tau_{\mathrm{v}}\right)$ can be determined.

\section{Methods}

\section{$\mathrm{Gd}-\mathrm{Zr} / \mathrm{PEO}_{6 \mathrm{k}}-\mathrm{b}-\mathrm{PAA}_{3 \mathrm{k}}$ HPIC formation}

HPICs were formed by mixing solutions of $\mathrm{PEO}_{6 \mathrm{k}}-\mathrm{b}-\mathrm{PAA}_{3 \mathrm{k}}$ $(0.1 \%$ wt $)$ (i.e. $\left.[\mathrm{AA}]=0.51 .10^{-3} \mathrm{~mol} . \mathrm{L}^{-1}\right)$ with solutions containing $\mathrm{Gd}\left(\mathrm{NO}_{3}\right)_{3} \cdot 6 \mathrm{H}_{2} \mathrm{O}$ and $\mathrm{ZrOCl}_{2} \cdot 8 \mathrm{H}_{2} \mathrm{O}$. Gadolinium and zirconium concentrations were adjusted in order to have a molar fraction of gadolinium $\rho_{\mathrm{Gd}}$ (see main text equation (2)) between 5 and $100 \%$ within the HPICs. The ratio $\rho_{\text {charge }}$ (see main text equation (1)) between the charges due to the metallic ions and that due to the polymers was set to be close to unity for all experiments. After mixing, the $\mathrm{pH}$ of the solutions was adjusted to $6.8-7$.

\section{$\mathrm{Gd}-\mathrm{Ga} / \mathrm{PEO}_{6 \mathrm{k}}-\mathrm{b}-\mathrm{PAA}_{3 \mathrm{k}}$ HPIC formation}

HPIC formation was done by mixing solutions of $\mathrm{PEO}_{6 \mathrm{k}}-\mathrm{b}-$ PAA $_{3 \mathrm{k}}\left(0.1 \%\right.$ wt) (i.e. [AA] $\left.=0.51 .10^{-3} \mathrm{~mol}^{-\mathrm{L}^{-1}}\right)$ upon solutions containing addition $\mathrm{Gd}\left(\mathrm{NO}_{3}\right)_{3} \cdot 6 \mathrm{H}_{2} \mathrm{O}$ and $\mathrm{Ga}\left(\mathrm{NO}_{3}\right)_{2} \cdot 6 \mathrm{H}_{2} \mathrm{O}$. Gadolinium and gallium concentrations were adjusted in order to have a molar fraction of gadolinium $\rho_{\mathrm{Gd}}=\left[\mathrm{Gd}^{3+}\right] /\left(\left[\mathrm{Ga}^{3+}\right]+\right.$ $\left[\mathrm{Gd}^{3+}\right]$ ) between 5 and $100 \%$ within the HPICs. The ratio $\rho_{\text {charge }}$ $=\left(3 \cdot\left[\mathrm{Gd}^{3+}\right]+3 \cdot\left[\mathrm{Ga}^{3+}\right]\right) /[\mathrm{AA}]$ between the charges due to the metallic ions and ones due to the polymers was set to be close to unity for all experiments (see main text). After mixing, $\mathrm{pH}$ of the solutions was adjusted to $6.8-7$.

Titration by ICP-AES of free Gd

Solutions of $\mathrm{PEO}_{6 \mathrm{k}}$-b-PAA $3 \mathrm{k}$ polymers $(0.1 \% \mathrm{wt})$ with various amount of $\mathrm{Gd}^{3+}$ and $\mathrm{ZrO}^{2+}$ were prepared to get HPICs solutions with $\rho_{\text {charge }}=1$ and $\rho_{\mathrm{Gd}}=100 \%, 25 \%$ or $10 \%$ in $2 \mathrm{~mL}$ of MilliQ water. After adjustment of the $\mathrm{pH}$ of the solutions to ca $6.8-7$, the $\mathrm{pH}$ was decreased by addition of $\mathrm{HCl}$ solution. The samples were then filtered with centrifugal filters (molecular weight cut-off $3 \mathrm{kDa}$ ) (Ultracel®-3K - Millipore Ireland Ltd) at $6500 \mathrm{rpm}$ for $40 \mathrm{~min}$. The filtered solution were then analyzed by ICP-AES.

Average number of coordinated water molecules on Europium ions in HPICs 
Solutions of $\mathrm{PEO}_{6 \mathrm{k}}-\mathrm{b}-\mathrm{PAA}_{3 \mathrm{k}}$ polymers $(0.1 \% \mathrm{wt})$ with various amounts of $\mathrm{Eu}^{3+}$ and $\mathrm{ZrO}^{2+}$ were prepared to get HPICs solutions with $\rho_{\text {charge }}=1$ and $\rho_{\mathrm{Eu}}$ from $100 \%$ to $5 \%$. After adjusting of the $\mathrm{pH}$ of the solutions to ca $6.8-7$, luminescence of the solutions was measured. The solutions were freeze-dried the redispersed in $\mathrm{D}_{2} \mathrm{O}$ with final concentrations equivalent to that in water. DLS experiments on such redispersed solution suggest that the HPICs are maintained during this process. Luminescence of the $\mathrm{D}_{2} \mathrm{O}$ solutions was then recorded. Using the equation proposed by R.M. Supkowski et al., ${ }^{23}$ the number (n) of water molecules coordinated to the europium ions within the HPICs was estimated.

\section{In vitro cytotoxicity}

Human HCT-116 colorectal cancer cells (CCL-247) were purchased from ATCC and grown in DMEM containing 4.5 g.11 glucose, GLUTAMax and supplemented with $10 \%$ of heatinactivated fetal bovine serum and $100 \mathrm{U} / \mathrm{ml}$ penicillin, and 100 $\mu \mathrm{g} . \mathrm{ml}-1$ streptomycin. Cells were maintained at $37^{\circ} \mathrm{C}$ in a humidified atmosphere containing $5 \% \mathrm{CO}_{2}$. Throughout the experiments, cells were tested negative for mycoplasma (MycoAlert mycoplasma detection kit, Lonza). The day before the experiments, 20,000 HCT-116 were seeded in 96-well plates. The day of experiment, cells were incubated for $24 \mathrm{~h}$ at $37{ }^{\circ} \mathrm{C}$ with increasing concentration of $\mathrm{Zr}$ - Gd HPICs (molar ratio: 2/3 in $\mathrm{Zr}$ and $1 / 3 \mathrm{Gd}$ ) and its individual components, respectively, PEO-PAA polymer and $\mathrm{Zr} / \mathrm{Gd}$ mixtures alone, at similar concentrations as those tested for HPICs. Viability was then assessed using PrestoBlue reagent (Invitrogen) according to the manufacturer's instructions. Briefly, after $24 \mathrm{~h}$ of incubation, cell culture medium was removed and cells were incubated for $30 \mathrm{~min}$ at $37^{\circ} \mathrm{C}$ with $100 \mu \mathrm{l}$ of $1 \mathrm{X}$ PrestoBlue reagent diluted in PBS, before reading absorbance on a plate reader at $570 \mathrm{~nm}$ and $600 \mathrm{~nm}$ Synergy H1 (Biotek, Winooski, VT, USA). Six biological replicates were produced and analyzed for each condition. Data analysis was performed using GraphPad Prism 8 (GraphPad Software, Inc., La Jolla, CA, USA) and data were expressed as mean \pm SEM. Statistical comparisons were performed using one-way analysis of variance (ANOVA) followed by Dunnett's post-test in comparison to the control condition. $* \mathrm{p}<0.05, * * \mathrm{p}<0.01, * * * \mathrm{p}<0.001$ and $* * * * \mathrm{p}<0.0001$.

The concentration of the solutions used for these experiments were the following: polymer alone $[\mathrm{PEO}-\mathrm{PAA}]=0.18 \% \mathrm{wt}$; mixture of zirconyl and gadolinium ions solutions alone $[\mathrm{Zr}]=$ $3.35 \mathrm{mM}$ and $[\mathrm{Gd}]=1.16 \mathrm{mM}$; HPIC solution with [PEO-PAA] $=0.19 \% \mathrm{wt},[\mathrm{Zr}]=3.34 \mathrm{mM}$ and $[\mathrm{Gd}]=1.11 \mathrm{mM}$.

\section{ASSOCIATED CONTENT}

Supporting Information. Additional results (DLS correlograms, gadolinium release, relaxivity measurements of Gd-Ga HPICs) can be found in the supporting information section. This material is available free of charge via the Internet at http://pubs.acs.org.

\section{AUTHOR INFORMATION}

\section{Corresponding Author}

* Christophe Mingotaud, Laboratoire des IMRCP, CNRS UMR 5623, University of Toulouse, Université Toulouse III - Paul Sabatier,

118, route de Narbonne 31062 Toulouse Cedex 9, France e-mail: cmingo@ chimie.ups-tlse.fr ;

* Jean-Daniel Marty, Laboratoire des IMRCP, CNRS UMR 5623, University of Toulouse, Université Toulouse III - Paul Sabatier, 118, route de Narbonne 31062 Toulouse Cedex 9, France e-mail: marty@chimie.ups-tlse.fr

\section{Author Contributions}

The manuscript was written through contributions of all authors.

\section{Funding Sources}

"Agence National pour la Recherche": ANR Hybrid MRI, n ANR19-CE09-0011-01); Toulouse Tech transfert and Region Occitanie (FESR_PREMAT-000025/prématuration 2017 Hybrid-MRI).

\section{ACKNOWLEDGMENT}

The authors thank the "Agence National pour la Recherche" for funding (ANR Hybrid MRI, $n^{\circ}$ ANR-19-CE09-0011-01) as well as the financial support of Toulouse Tech transfert and Region Occitanie (FESR_PREMAT-000025/prématuration 2017 HybridMRI), the COST CA15209 Action "European Network on NMR Relaxometry", and the support and the use of resources of InstructERIC, a landmark ESFRI project, and specifically the CERM/CIRMMP Italy center. ESRF is acknowledged for provision of beamtime on the ID02. The authors wish also to thank Dr M. Sztucki for his assistance during the SAXS measurements as well as Dr. Baptiste Amouroux for various experiments.

\section{ABBREVIATIONS}

HPIC, hybrid polyion complexe; PEO, poly(ethylene oxide) ; PAA, poly(acrylic acid); MRI, magnetic resonance imaging; NMRD, nuclear magnetic relaxation dispersion.

\section{REFERENCES}

1. Nagarajan, R., Self-Assembly: From Surfactants to Nanoparticles. Wiley: Hoboken, NJ, 2018; p 368.

2. Magana, J. R.; Sproncken, C. C. M.; Voets, I. K., On Complex Coacervate Core Micelles: Structure-Function Perspectives. Polymers (Basel) 2020, 12 (9), 1953.

3. Sohn, H.; Shin, H.-W.; Lee, S.-M., Metal-Mediated Morphology Regulation of Self-Assembled Double-Hydrophilic Block Copolymers. ACS Macro Letters 2020, 9 (4), 600-605.

4. Shin, H.-W.; Sohn, H.; Jeong, Y.-H.; Lee, S.-M., Construction of Paramagnetic Manganese-Chelated Polymeric Nanoparticles Using Pyrene-End-Modified Double-Hydrophilic Block Copolymers for Enhanced Magnetic Resonance Relaxivity: A Comparative Study with Cisplatin Pharmacophore. Langmuir 2019, 35 (19), 6421-6428.

5. Layrac, G.; Gérardin, C.; Tichit, D.; Harrisson, S.; Destarac, M., Hybrid polyion complex micelles from poly(vinylphosphonic acid)-based double hydrophilic block copolymers and divalent transition metal ions. Polymer 2015, 72, 292-300.

6. Tarasov, K.; Houssein, D.; Destarac, M.; Marcotte, N.; Gerardin, C.; Tichit, D., Stable aqueous colloids of $\mathrm{ZnS}$ quantum dots prepared using double hydrophilic block copolymers. New J. Chem. 2013, 37 (2), 508-514.

$7 . \quad$ Sanson, N.; Bouyer, F.; Destarac, M.; In, M.; Gérardin, C., Hybrid Polyion Complex Micelles Formed from Double Hydrophilic Block Copolymers and Multivalent Metal Ions: Size Control and Nanostructure. Langmuir 2012, 28 (8), 3773-3782.

8. Uchman, M.; Procházka, K.; Gatsouli, K.; Pispas, S.; Špírková, M., CdS-containing nano-assemblies of double hydrophilic block copolymers in water. Colloid. Polym. Sci. 2011, 289 (9), 10451053.

9. $\quad$ Frangville, C.; Li, Y.; Billotey, C.; Talham, D. R.; Taleb, J.; Roux, P.; Marty, J.-D.; Mingotaud, C., Assembly of Double-Hydrophilic Block Copolymers Triggered by Gadolinium Ions: New Colloidal MRI Contrast Agents. Nano Lett. 2016, 16 (7), 4069-4073.

10. $\quad$ Puchberger, M.; Kogler, F. R.; Jupa, M.; Gross, S.; Fric, H.; Kickelbick, G.; Schubert, U., Can the Clusters $\mathrm{Zr}_{6} \mathrm{O}_{4}(\mathrm{OH})_{4}(\mathrm{OOCR})_{12}$ and $\left[\mathrm{Zr}_{6} \mathrm{O}_{4}(\mathrm{OH})_{4}(\mathrm{OOCR})_{12}\right]_{2}$ Be Converted into Each Other? Eur. J. Inorg. Chem. 2006, 2006 (16), 3283-3293. 
11. Schubert, U., Polymers Reinforced by Covalently Bonded Inorganic Clusters. Chem. Mater. 2001, 13 (10), 3487-3494.

12. Lee, D. B.; Roberts, M.; Bluchel, C. G.; Odell, R. A., Zirconium: biomedical and nephrological applications. ASAIO J. 2010, 56 (6), 550-6.

13. Solovkin, A. S.; Tsvetkova, Z. N., The chemistry of aqueous solutions of zirconium salts (does the zirconyl ion exist?). Rus. Chem. Rev. 1962, 31 (11), 656-669.

14. Singhal, A.; Toth, L. M.; Lin, J. S.; Affholter, K., Zirconium(IV) Tetramer/Octamer Hydrolysis Equilibrium in Aqueous Hydrochloric Acid Solution. J. Am. Chem. Soc. 1996, 118 (46), 1152911534.

15. Singhal, A.; Toth, L. M.; Beaucage, G.; Lin, J.-s.; Peterson, J., Growth and Structure of Zirconium Hydrous Polymers in Aqueous Solutions. J. Colloid Interface Sci. 1997, 194 (2), 470-481.

16. Bremholm, M.; Birkedal, H.; Iversen, B. B.; Pedersen, J. S., Structural Evolution of Aqueous Zirconium Acetate by Time-Resolved Small-Angle X-ray Scattering and Rheology. J. Phys. Chem. C Nanomater. Interfaces 2015, 119 (22), 12660-12667.

17. Hennig, C.; Weiss, S.; Kraus, W.; Kretzschmar, J.; Scheinost, A. C., Solution Species and Crystal Structure of Zr(IV) Acetate. Inorg. Chem. 2017, 56 (5), 2473-2480.

18. Swift, T.; Swanson, L.; Geoghegan, M.; Rimmer, S., The $\mathrm{pH}$-responsive behaviour of poly(acrylic acid) in aqueous solution is dependent on molar mass. Soft Matter 2016, 12 (9), 2542-2549.

19. Arnold, R., The titration of polymeric acids. J. Colloid Sci. 1957, 12 (6), 549-556.

20. Devine, C. D. The stability constants of some carboxylate complexes of the trivalent lanthanons. Iowa State University, 1969

21. Choppin, G. R.; Peterman, D. R., Applications of lanthanide luminescence spectroscopy to solution studies of coordination chemistry. Coord. Chem. Rev. 1998, 174 (1), 283-299.

22. Haas, Y.; Stein, G., Pathways of radiative and radiationless transitions in europium(III) solutions. Role of solvents and anions. $J$. Phys. Chem. 1971, 75 (24), 3668-3677.

23. Supkowski, R. M.; Horrocks, W. D., On the determination of the number of water molecules, q, coordinated to europium(III) ions in solution from luminescence decay lifetimes. Inorg. Chim. Acta 2002, $340,44-48$.

$24 . \quad$ Young, I. R.; Clarke, G. J.; Baffles, D. R.; Pennock, J. M.; Doyle, F. H.; Bydder, G. M., Enhancement of relaxation rate with paramagnetic contrast agents in NMR imaging. J. Comput. Tomogr. 1981, 5 (6), 543-547.

25. Bottomley, P. A.; Foster, T. H.; Argersinger, R. E.; Pfeifer, L. M., A review of normal tissue hydrogen NMR relaxation times and relaxation mechanisms from 1-100 MHz: Dependence on tissue type, NMR frequency, temperature, species, excision, and age. Med. Phys. 1984, 11 (4), 425-448.

26. Tseng, C.-L.; Shih, I. L.; Stobinski, L.; Lin, F.-H., Gadolinium hexanedione nanoparticles for stem cell labeling and tracking via magnetic resonance imaging. Biomaterials 2010, 31 (20), 54275435.

27. Oostendorp, M.; Douma, K.; Hackeng, T. M.; Post, M. J.; van Zandvoort, M. A. M. J.; Backes, W. H., Gadolinium-labeled quantum dots for molecular magnetic resonance imaging: R1 versus R2 mapping. Magn. Reson. Med. 2010, 64 (1), 291-298.

28. Bertini, I.; Luchinat, C.; Parigi, G.; Ravera, E., NMR of Paramagnetic Molecules, 2nd Edition. 2016.

29. Amoroso, A. J.; Pope, S. J. A., Using lanthanide ions in molecular bioimaging. Chem. Soc. Rev. 2015, 44 (14), 4723-4742.

30. Elorza, V., [Toxicity of metallic ions to Asperigillus nidulans]. Microbiol. Esp. 1969, 22 (2), 131-7.

31. Bruce, D. W.; Hietbrink, B. E.; DuBois, K. P., The acute mammalian toxicity of rare earth nitrates and oxides. Toxicol. Appl. Pharmacol. 1963, 5 (6), 750-759.

32. Haley, T. J.; Raymond, K.; Komesu, N.; Upham, H. C., Toxicological and pharmacological effects of gadolinium and samarium chlorides. Br. J. Pharmacol. Chemother. 1961, 17 (3), 526-532.

33. Graca, J. G.; Davison, F. C.; Feavel, J. B., Comparative Toxicity of Stable Rare Earth Compounds. Arch. Environ. Health 1962, 5 (5), 437-444
34. Gillis, P.; Koenig, S. H., Transverse relaxation of solvent protons induced by magnetized spheres: Application to ferritin, erythrocytes, and magnetite. Magn. Reson. Med. 1987, 5 (4), 323-345.

35. L. Villaraza, A. J.; Bumb, A.; Brechbiel, M. W., Macromolecules, Dendrimers, and Nanomaterials in Magnetic Resonance Imaging: The Interplay between Size, Function, and Pharmacokinetics. Chem. Rev. 2010, 110 (5), 2921-2959.

36. Ravera, E.; Fragai, M.; Parigi, G.; Luchinat, C., Different flavors of diffusion in paramagnetic systems: Unexpected NMR signal intensity and relaxation enhancements. J. Magn. Res. Open 2020, 2-3, 100003 .

37. Mastarone, D. J.; Harrison, V. S. R.; Eckermann, A. L.; Parigi, G.; Luchinat, C.; Meade, T. J., A Modular System for the Synthesis of Multiplexed Magnetic Resonance Probes. J. Am. Chem. Soc. 2011, 133 (14), 5329-5337.

38. Spanoghe, M.; Lanens, D.; Dommisse, R.; Van der Linden, A.; Alderweireldt, F., Proton relaxation enhancement by means of serum albumin and poly-1-lysine labeled with DTPA-Gd3+: Relaxivities as a function of molecular weight and conjugation efficiency. Magn. Reson. Imaging 1992, 10 (6), 913-917.

39. Li, Y.; Beija, M.; Laurent, S.; Elst, L. v.; Muller, R. N.; Duong, H. T. T.; Lowe, A. B.; Davis, T. P.; Boyer, C., Macromolecular Ligands for Gadolinium MRI Contrast Agents. Macromolecules 2012 , 45 (10), 4196-4204.

40. Adkins, C. T.; Dobish, J. N.; Brown, C. S.; Mayrsohn, B.; Hamilton, S. K.; Udoji, F.; Radford, K.; Yankeelov, T. E.; Gore, J. C.; Harth, E., High relaxivity MRI imaging reagents from bimodal star polymers. Polym. Chem. 2012, 3 (2), 390-398.

41. McLeod, S. M.; Robison, L.; Parigi, G.; Olszewski, A.; Drout, R. J.; Gong, X.; Islamoglu, T.; Luchinat, C.; Farha, O. K.; Meade, T. J., Maximizing Magnetic Resonance Contrast in Gd(III) Nanoconjugates: Investigation of Proton Relaxation in Zirconium Metal-Organic Frameworks. ACS App. Mat. Int. 2020, 12 (37), 4115741166.

42. Li, H.; Parigi, G.; Luchinat, C.; Meade, T. J., Bimodal Fluorescence-Magnetic Resonance Contrast Agent for Apoptosis Imaging. J. Am. Chem. Soc. 2019, 141 (15), 6224-6233.

43. Rotz, M. W.; Culver, K. S. B.; Parigi, G.; MacRenaris, K. W.; Luchinat, C.; Odom, T. W.; Meade, T. J., High Relaxivity Gd(III)DNA Gold Nanostars: Investigation of Shape Effects on Proton Relaxation. ACS Nano 2015, 9 (3), 3385-3396.

44. Aime, S.; Frullano, L.; Geninatti Crich, S., Compartmentalization of a Gadolinium Complex in the Apoferritin Cavity: A Route To Obtain High Relaxivity Contrast Agents for Magnetic Resonance Imaging. Angew. Chem. Int. Ed. 2002, 41 (6), 1017-1019.

45. $\quad$ Fragai, M.; Ravera, E.; Tedoldi, F.; Luchinat, C.; Parigi, G., Relaxivity of Gd-Based MRI Contrast Agents in Crosslinked Hyaluronic Acid as a Model for Tissues. Chemphyschem 2019, 20 (17), 2204 2209.

46. Tang, J.; Sheng, Y.; Hu, H.; Shen, Y., Macromolecular MRI contrast agents: Structures, properties and applications. Prog. Polym. Sci. 2013, 38 (3), 462-502.

47. Jin, M.; Zhang, Y.; Gao, G.; Xi, Q.; Yang, Y.; Yan, L.; Zhou, H.; Zhao, Y.; Wu, C.; Wang, L.; Lei, Y.; Yang, W.; Xu, J., MRI Contrast Agents Based on Conjugated Polyelectrolytes and Dendritic Polymers. Macromol. Rapid Commun. 2018, 39 (16), 1800258.

48. Huang, Z.; Chen, Y.; Liu, D.; Lu, C.; Shen, Z.; Zhong, S.; Shi, G., Gadolinium-conjugated star-block copolymer polylysine-modified polyethylenimine as high-performance T1 MR imaging blood pool contrast agents. RSC Advances 2018, 8 (9), 5005-5012.

49. Caravan, P., Strategies for increasing the sensitivity of gadolinium based MRI contrast agents. Chem. Soc. Rev. 2006, 35 (6), 512 523.

50. Kowalewski, J.; Luchinat, C.; Nilsson, T.; Parigi, G., Nuclear Spin Relaxation in Paramagnetic Systems: Electron Spin Relaxation Effects under Near-Redfield Limit Conditions and Beyond. $J$. Phys. Chem. A 2002, 106 (32), 7376-7382.

51. Bertini, I.; Luchinat, C.; Parigi, G.; Ravera, E., NMR of Paramagnetic Molecules (Second Edition). Elsevier: Boston, 2017; p 1-24. 52. Lilley, L. M.; Du, K.; Krzyaniak, M. D.; Parigi, G.; Luchinat, C.; Harris, T. D.; Meade, T. J., Effect of Magnetic Coupling on 
Water Proton Relaxivity in a Series of Transition Metal GdIII Complexes. Inorg. Chem. 2018, 57 (10), 5810-5819.

53. Caravan, P.; Farrar, C. T.; Frullano, L.; Uppal, R., Influence of molecular parameters and increasing magnetic field strength on relaxivity of gadolinium- and manganese-based T1 contrast agents. Contrast Media Mol. Imaging 2009, 4 (2), 89-100.

54. Kojima, C.; Turkbey, B.; Ogawa, M.; Bernardo, M.; Regino, C. A. S.; Bryant, L. H.; Choyke, P. L.; Kono, K.; Kobayashi, H., Dendrimer-based MRI contrast agents: the effects of PEGylation on relaxivity and pharmacokinetics. Nanomed. Nanotechnol. Biol. Med. 2011, 7 (6), 1001-1008

55. Delongeas, J. L.; Burnel, D.; Netter, P.; Grignon, M.; Mur, J. M.; Royer, R. J.; Grignon, G., Toxicity and pharmacokinetics of zirconium oxychloride in mice and rats. J. Pharmacol. 1983, 14 (4), 437 47.

56. Dionzou, M.; Morere, A.; Roux, C.; Lonetti, B.; Marty, J. D.; Mingotaud, C.; Joseph, P.; Goudouneche, D.; Payre, B.; Leonetti, M.; Mingotaud, A. F., Comparison of methods for the fabrication and the characterization of polymer self-assemblies: what are the important parameters. Soft Matter 2016, 12 (7), 2166-2176.

57. Narayanan, T.; Sztucki, M.; Van Vaerenbergh, P.; Leonardon, J.; Gorini, J.; Claustre, L.; Sever, F.; Morse, J.; Boesecke, P., A multipurpose instrument for time-resolved ultra-small-angle and coherent X-ray scattering. J. Appl. Crystallogr. 2018, 51 (6), 1511-1524.

58. Gineste, S.; Di Cola, E.; Amouroux, B.; Till, U.; Marty, J.D.; Mingotaud, A.-F.; Mingotaud, C.; Violleau, F.; Berti, D.; Parigi, G.; Luchinat, C.; Balor, S.; Sztucki, M.; Lonetti, B., Mechanistic Insights into Polyion Complex Associations. Macromolecules 2018, 51 (4), 1427-1440.

59. SAXS utilities. Available online: http://www.sztucki.de/SAXSutilities/.

60. Bertini, I.; Galas, O.; Luchinat, C.; Parigi, G., A Computer Program for the Calculation of Paramagnetic Enhancements of Nuclear-Relaxation Rates in Slowly Rotating Systems. J. Magn. Reson., Ser A 1995, 113 (2), 151-158.

61. Bertini, I.; Kowalewski, J.; Luchinat, C.; Nilsson, T.; Parigi, G., Nuclear spin relaxation in paramagnetic complexes of $\mathrm{S}=1$ : Electron spin relaxation effects. J. Chem. Phys. 1999, 111 (13), 5795-5807. 62. Bertini, I.; Luchinat, C.; Parigi, G., 1H NMRD profiles of paramagnetic complexes and metalloproteins. In Adv. Inorg. Chem., Academic Press: 2005; Vol. 57, pp 105-172. 


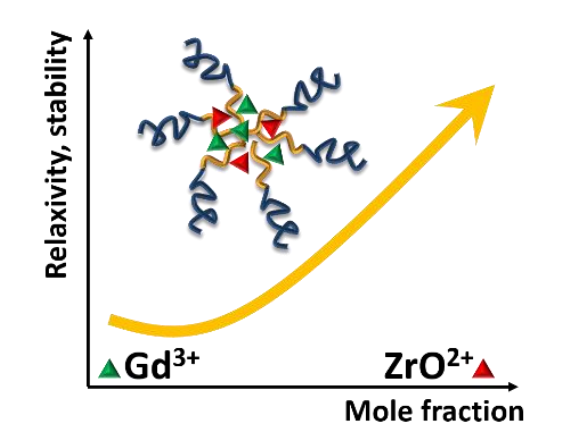

